TID-4500, UC-35

Nuclear Explosions -

Peaceful Applications

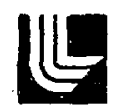

LAMRENCE LNERMORE LABORATOAY

inversity of Caftomia/Livermora, Caftomia/94550

UCRI- $\$ 1235$

\title{
A METHOD FOR ESTIMATING HEIGHTS OF WATER WAVES GENERATED BY UNDERWATER CRATERING EXPLOSIONS
}

\author{
W. J, Garcia, Jr.
}

MS, date: June 7, 1972

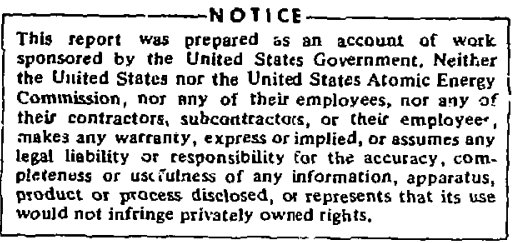

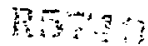




\section{Contents}

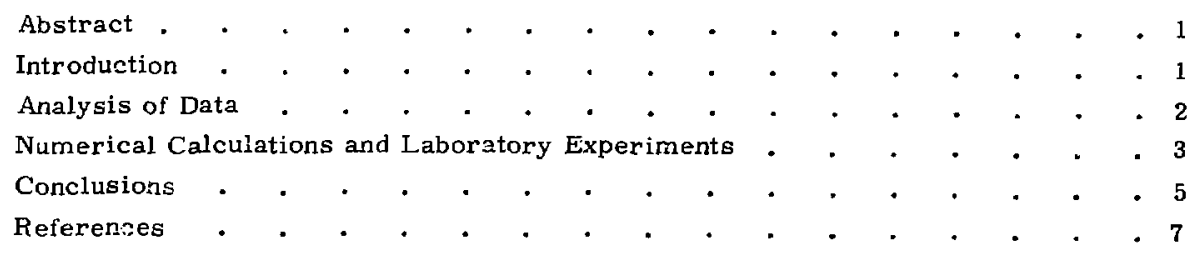




\title{
A METHOD FOR ESTIMATING HEIGHTS OF WATER WAVES GENERATED BY UNDERWATER CRATERING EXPLOSIONS
}

\begin{abstract}
This paper describes a method to predict the wave heights of water waves generated by underwater cratering explosions. The method of predicting wave heights is based upon underwater explosion data, the results of numerical model simulations, and laboratory experiments.

We found that the ratio of wave height to source displacement is independent of the details of the displacement-time history of the source motion. A method for simulating water wave generation by underwater cratering explosions with a numerical model is also discussed.
\end{abstract}

\section{Introduction}

In order to predict wave heights and wave crest elevations of waves generated by underwater cratering explosions in shallow water, the empirical data from explosion tests are analyzed and the results are checked with a combination of numerical calculations and laboratory experiments. If nuclear explosives are used to excavate harbors, one safety feature that musi be considered is the flooding caused by the waves generated by the explosion. Impulsively generated waves from nuclear explosions have many of the same characteristics as other impulsively generated waves such as tsunamis (produced by ocean floor movements from earthquakes) or waves produced by landslides into reservoirs or bays. Van Dorn' published data comparing waves produced by nuclear explosions with a large tsunami. The major difference between explosion generated waves and other impulsively generated waves is the size of the source motion compared with the water depth. Source displacement for the class of underwater explosions under consideration is large, about ten times the water depth, while the source displacement for tsunamis is smail, less than one hundredth of the water depth. In spite of the differences in source motion, the waves have the sarro characteristics. Both systems are dispersive and both travel at about the shallaw water wave speed. Since the similarities in the systems are much greater than their difference, the same type of analysis can be used for both. In addition, the empirical data from underwater cratering explosions are particularly useful in 
developing relations between the explosive yield and source motion. These data have been published in a previous paper on this subject. ${ }^{2}$

\section{Analysis of Data}

The water wave data from all the underwater cratering explosions in shallow water were examined in light of the results of the laboratory experiments and numerical calculations for impulsively generated waves. The principal result, as it applies to explosion generated waves for large source motions, is that the ratio of the elevation of the first wave crest to the source displacement is independent of source speed. The source speed is expressed here in terms of a rondimensional Froude number for the source. The Froude number, $\mathrm{N}_{F}$, for the source is defined as the total source displacement, $\lambda$, divided by the product of the time for tne total displacement, $\tau$, and tne square root of the product of acceleration of gravity, $g$, and water depth, $d$ in the vicinity of the source. The explosion generated waves tend to have a large ratio of source displacement to water depth. The average $\lambda / d$ ratio for the underwaier cratering explosions that have been detonated is about 9.3 with a low of 5.1 and a high of 15.1. For explosion generated waves, the source displacement, $\lambda$, is assumed to be equal to the maximum radius of the water column, $R_{c}$. The source for explosion waves is actually the bubble of expanding gases, but the maximum "adius of the bubble and water column are very close, and the water column radius can be readily measured.

The water column radius was correlated to the yield and depth of burial of the exilosion, resulting in the equation

$$
R_{c}=156[Y /(D+33)]^{1 / 3} \text {. }
$$

Here, $R_{c}$ is the maximum radius of the water column in feet, $Y$ is the yield of the explosive in tons of TNT equivalent, anci $D$ is the depth of burial of the explosive below the water surface in feet. Also, in tree previous paper, ${ }^{1}$ the wave height defined as the vertical distance between the first crest and following trough was related to the water column radius and distance from the source by the equation

$$
H=0.16 R_{c}^{2} / R
$$

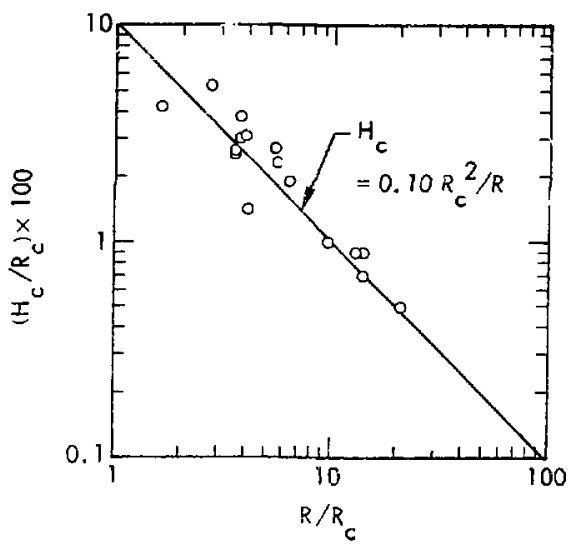

Fig. 1. Ratio of elevation of first crest to water column radius, $\mathrm{H}_{\mathrm{C}} / \Gamma_{\mathrm{i}} \mathrm{c}$ vs ratio of distance from source to water column radius, $R / R_{C}$. All available shallow underwiter and underwater cratering data. 
where $\mathrm{H}$ is the wave height as defined above, $R$ is the radial distance from the source, and $R_{c}$ is the maximurn radius of the water column.

The elevation of the first crest above the still water level, $\mathbf{H}_{\mathrm{c}^{\prime}}$ can also be determined in terms of the maximum water column radius and distance irom the source, Figure 1 is a plot of $\mathrm{H}_{c} / \mathrm{R}_{\mathrm{c}}$ $v s R / R_{c}$ for all available data from cratering explosions in shallow water. The elevation of the first crest can be expressed by the equation

$$
\mathrm{H}_{\mathrm{c}}=0.10 \mathrm{R}_{\mathrm{c}}^{2} / \mathrm{R} \text {. }
$$

Either the elevation of the first crest or wave height cf the first wave can be calculated quickly and easily from the above equations. It is difficult to put accuracy limits on any these equations since there have on $y$ been a few underwater craterin's experiments conducted. Equations 1, 2, ald 3 provide a good approximation considering the wide differences in wave heigits due to local variations in water depth and other surface disturbances. If the wave moves into the vicinity of shore or through water of changing depth, there will se diffraction and refraction of the wav that will modify the wave height. This may be of great importance with regard to floodir.y or other wave damage.

\section{Numerical Calculations and Laboratory Experiments}

An experimental program was carried out at the Hydraulic Engineering Laboratory at the University of Califoinia, Berkeley in order to ge.in more information about impulsively generated water waves and also to verify the Eulerinn incompressible hydrodynamic modeling technique ABMAC (Arbitrary Eoundary Marker and Cell) with nature. ${ }^{3}$ The numerical calculations also supplemented the data provided by the laboratory experiments. The purpose $\mathrm{ci}$ the program, both laboratory and numerical, was not to specifically model explosion generated w.ves, but to generally research the relationship between source motion and wave characteristics, consequently simple configurations were chosen for the sources. Experiments and calculations were performed for a vertical wall source where the wall moves as a plunger, horizontally into the fluid; slope wall sources with slopes of 1 vertical to 1 horizontal and 1 vertical to 2 horizonial; and underwater step source where the step height was one-half the water depth. All experinents were performed in two dimensions, the numerical calculations were also performed in two dimensions to conform to the laboratory experiments. A detailed discussion of the laboratory experiments is given by Garcia. 4

The vertical wall coniliguration was designed to give general data concerning impulsively generated waves. The results of the vertical wall calculations are shown in Fig. 2. The Froude number, $\mathrm{N}_{\mathrm{F}}$, equals the total displacement of the source, $\lambda$, (wall in this case) divided by the product of the time for the total displacement, $\tau$, and the square root of the product of acceleration of gravity, $g$, and 


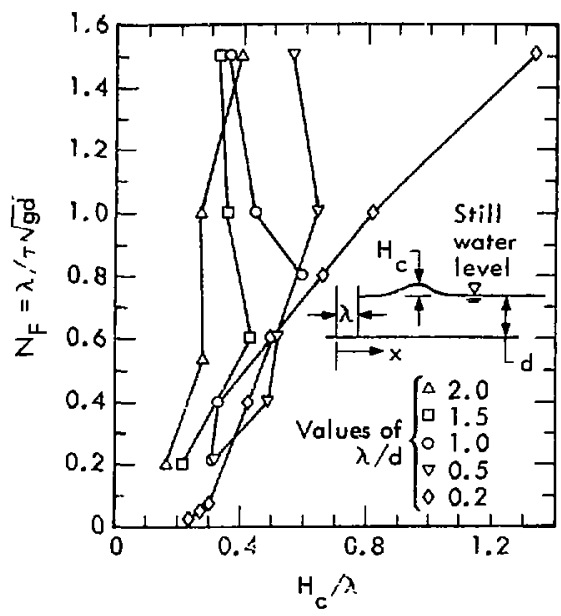

Fig. 2. Relation between $N_{F}=\lambda / r \sqrt{g d}$ and $\mathrm{H}_{\mathrm{C}} / \lambda$ for vertical wall for $\mathrm{d}=0.50 \mathrm{ft}$ at $\mathrm{X}=5.0 \mathrm{ft}$.

water depth, $d$. The $\mathrm{N}_{F}$ number vs the ratio of the elevation of the first crest above the still water level to total source displacement, $\mathrm{H}_{\mathrm{c}} / \lambda$, for various values of the ratio of source displacement to water depth, $\lambda / d$. There is actually a considerable amount of scatter in the data in Fig. 2 due to the random nature of breaking weves. Since there is a stochastic element in water waves, they cannot be repeated exactly. This problem is especially critical in the case of breaking waves and waves close to the source. From Fig. 2, there are two regions where the ratio $\mathrm{H}_{\mathrm{C}} / \lambda$ is sot greatly dependent on the Froude number for the source, $\mathrm{N}_{\mathrm{F}}$; these regions are for low Froude number and for large $\lambda / d$. The latter region is of particular impertance with regard to explosion generated waves since the source displacements associated with explosions are large. The trend of these data indicate that in the regime of explosion generated waves where $\lambda / d$ averages about 10 , the ratio $\mathrm{H}_{\mathrm{c}} / \lambda$ should be independent of the Froude number $\mathrm{N}_{\mathrm{F}}$. The fact that explosion generated waves provide such a good correlation between wave crest elevation or wave height and the water column radius is a further indication that the particulars of the displacement-time history for the source are unimportant. For the explosion generated waves, the water column radius, $R_{c^{\prime}}$ is the analog of the source cisplaceinent, $\lambda$. Close to the sururce (where $X / d=10.0$ in Fig. 2), it can be assumed that $R=R_{c}$ and Eq. 3 can be rewritten as

$$
\mathrm{H}_{\mathrm{c}} / \mathrm{R}_{\mathrm{c}}=0.10
$$

which is completely consistent with the laboratory experiments and numerical calculations for the vertical wall case. One important result of this analysis is the suggestion of a model of initial conditions for sinulaiing an t.nderwater cratering explosion with a numerical model such as ABMAC. Since the details of the source motion are not important, the explosion can be simulated by a vertical wall moving horizontally into the fluid with a maximum displacement equal to the witer column radius calculated from Eq. 1 and a time for the motion estimated from the mound velocity. The wall should be displaced back to its initial position quickly after it has reached its maximum displacement in order to allow the water to flow back into the area that would be the crater. This type of numerical simulation could be done in cylindrical symmetry and include imporiant features of unde:-water 
topography in order to give a more reliable estimate of wave characteristics than the use of Eqs. 2 or 3. There are problems associated with the numerical simulations, however, The problem running time and computer memory capacity are two major limitations. Due to the high velocities and large pressure changes associated with source motion simulating cxplosions, the time step between problem solution cycles must be small and the solution of the pressure equation requires a large number of iterations, both of which increase problem running time. Adidionally since the source motion is large, a large area must be modeled requiring a large computational mesh which increases both the computer memcry requirements and running time.

The siope wall and uncierwater step experiments were designed to approximate weter wave generation by a moving beach slope and submarine ridge, respectively. There were insufficient data taken for these cases to draw any conclusions. Ho Never, the results are consistent with the results of the vertical wall experiments and calculations.

The second purpose of the laboratory experiments was to verify that the numeric al modeling technique represents nature accurately, Motion pictures were taken of all the laboratory experiments. The water surface profile measured from the movie frames for ten of the experiments was compared to the water surface profiles calculated with the numerical model for identical conditions. The experiments chosen for comparison were those which represented the greatest variations in conditions for the vertical wall, slope walls, and underwater step. In all cases, both the laboratory and numerically calculated water surface profiles had exactly the same form. The maximum error between the laboratory and numerical profiles was $0.02 \mathrm{ft}$. The wave heights for all the experiments Varied from. $0.05 \mathrm{ft}$ to $0.30 \mathrm{ft}$. Much of this error is due to the fact that the movie film could not be read any closer than $\pm 0.01 \mathrm{ft}$. The conclusion of the comparison is that the numerical model is a very good simulation of nature for this type of problem. A complete discussion of all the experiments and the comparisons between the laboratory experiments and numerical calculations is given by Garcia. The discussion was omitted here in tie interests of brevity since it does not contribute directly to the problem of estimating wave crest elevations and wave heights of waves produced by underwater cratering explosions.

\section{Conclusions}

'fhe combingtion of the few enipirical data, numerical model calculations, and laboratory experiments has provided a useful method for estimating the crest elevat ion and wave height of the first wave resulting from the detonation of an under- water cratering explosion. The crest elevation or wave height can be related directly to the yield and cepth of burial of the explosive thus giving a quick answer for the wave elevation or wave height at any distance from the source. Refined 
estimates can further be made by numerical simulation of the cratering explosion using the maximum column radius from Eq. 1 for the source displacement of a vertical wall source. Further refinements can be made by applying diffraction and refraction theory (Wiegel ${ }^{5}$ ) to the wave as it moves away from the source into water of varying depth. This may not be a major consideration close to the source, but as the wave moves farther away it will be focused or dispersed depending upon the bottom topography it encounters. 


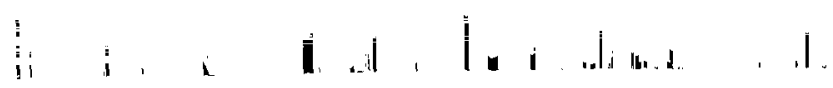

\section{References}

1. W. G. Van Dorn, J. Geophysical Res. 66, 11, 3845-3862 (1961).

2. W. J. Garsia, Water Waves Produced by Cratering Explosions in Shallow Water, Lawrence Livermore Laboratory, Rept. UCRL-50940 (1970).

3. J. A. Viecelli, J. Computational Phys. 8. 119-143 (1971).

4. W. J. Garcia, A Study of Water Waves Generated by Tectonic Displacements, University of California, Berkeley, Hydraulic Engineering Laboratory, Rept, HEL $16-9\langle 1972\rangle$.

5. R. I. Wiegel, Oceanographical Engineering, (Prentice-Hall, Inc, Fnglewood Cliffs, N. J., 1964). 
